\title{
Methamphetamine potentiates HIV-1 gp120-mediated autophagy via Beclin-1 and Atg5/7 as a pro-survival response in astrocytes
}

\author{
Lu Cao ${ }^{1}$, Mingui Fu², Santosh Kumar ${ }^{3}$ and Anil Kumar ${ }^{\star}, 1$
}

\begin{abstract}
Methamphetamine (METH), a commonly used controlled substance, is known to exacerbate neuropathological dysfunction in HIVinfected individuals. The neuropathological manifestation results from cell death or dysfunction in the central nervous system (CNS) wherein autophagy is expected to have an important role. Autophagy is generally considered protective during deprivation/ stress. However, excessive autophagy can be destructive, leading to autophagic cell death. This study was designed to investigate if METH and HIV-1 gp120 interact to induce autophagy in SVGA astrocytes, and whether autophagy is epiphenomenal or it has a role in METH- and gp120-induced cytotoxicity. We found that METH and gp120 Illb caused an increase in LC3II level in astrocytes in a dose- and time-dependent manner, and the level of LC3Il was further increased when the cells were treated with METH and gp120 IIllb in combination. Next, we sought to explore the mechanism by which METH and gp120 induce the autophagic response. We found that METH induces autophagy via opioid and metabotropic glutamate receptor type 5 (mGluR5) receptors. Other than that, signaling proteins Akt, mammalian target of rapamycin (mTOR), Beclin-1, Atg5 and Atg7 were involved in METH and gp120-mediated autophagy. In addition, long-term treatment of METH and gp120 Illb resulted in cell death, which was exacerbated by inhibition of autophagy. This suggests that autophagy functions as a protective response against apoptosis caused by METH and gp120. This study is novel and clinically relevant because METH abuse among HIV-infected populations is highly prevalent and is known to cause exacerbated neuroAIDS.
\end{abstract}

Cell Death and Disease (2016) 7, e2425; doi:10.1038/cddis.2016.317; published online 20 October 2016

Although the introduction of highly active antiretroviral therapy (ART) has significantly reduced the incidence of HIV-associated dementia (HAD), HIV-associated neurocognitive disorders (HAND) remains a major problem in sizeable number of infected individuals. ${ }^{1,2}$ This is compounded by the fact that mechanism of HIV neuropathogenesis is poorly understood. There are three major cell types in the brain of which only microglia and astrocytes are susceptible to viral infection. Astrocytes comprise approximately $70 \%$ of the brain, and are thought to have an important role in pathogenesis of HAND. ${ }^{3}$ The interactions between astrocytes and neurons are crucial for neuronal survival under the pathological condition. An impairment in the functions of astrocytes can negatively impact the neurons, leading to neurodegenerative diseases. For example, apoptotic astrocytes has been found in the brains of patients with HAD. ${ }^{4}$ It is generally considered that HIV-1 induces neurotoxicity via direct as well as indirect effects of the viral proteins on astrocytes. ${ }^{5}$ We among others have earlier shown that variety of HIV proteins including HIV-1 gp120, ${ }^{6-9}$ Tat, $^{10,11}$ Nef $^{12,13}$ and Vpr $^{14}$ can cause central nervous system (CNS) toxicity by exerting their effect on astrocytes.

Methamphetamine (METH) is one of the most commonly used recreational drugs in the United States, and its prevalence is increased in HIV-infected population $(\sim 15 \%)$ compared with the normal population. ${ }^{15}$ It is a potent psychostimulant that causes neurotoxicity via several mechanisms such as damage of both dopamine and serotonin neurons in the CNS, ${ }^{16,17}$ induction of oxidative stress ${ }^{18}$ and dysregulation of glutamate uptake in $\mathrm{CNS} .^{19}$ In addition, the use of METH also leads to clinical symptoms such as rapid and irregular heartbeat, delirium, psychosis and heart failure. $^{20,21}$ METH has been shown to exacerbate HIVassociated neurotoxicity in the CNS. ${ }^{22}$ Previous studies have proved that METH and gp120 work synergistically to increase the level of proinflammatory cytokine IL-6 and induce oxidative stress, which lead to apoptosis in astrocytes. ${ }^{23,24}$

Autophagy is a regulated degradative process in eukaryotic cells that allows recycling of cellular components under stress condition, and protects the cells from dying. ${ }^{25}$ During this

\footnotetext{
${ }^{1}$ Division of Pharmacology and Toxicology, School of Pharmacy, University of Missouri-Kansas City, Kansas City, MO, USA; '2Department of Basic Medical Science, School of Medicine, University of Missouri-Kansas City, Kansas City, MO, USA and ${ }^{3}$ Department of Pharmaceutical Sciences, College of Pharmacy, University of Tennessee Health Science Center, Memphis, TN, USA

${ }^{*}$ Corresponding author: A Kumar, Division of Pharmacology and Toxicology, School of Pharmacy, University of Missouri-Kansas City, 2464 Charlotte Street, Kansas City, MO 64108, USA. Tel: +1 816235 1792; Fax: +1 816235 1776; E-mail: kumaran@umkc.edu

Abbreviations: METH, methamphetamine; CNS, central nervous system; MAPLC3, microtubule-associated protein-1 light chain 3; HAD, HIV-associated dementia; HAND, HIV-associated neurocognitive disorders; mTOR, mammalian target of rapamycin; 3-MA, 3-methyladenine; PI3K, phosphoinositide 3-kinase; nor-BNI, norbinaltorphimine dihydrochloride; mGluR5, metabotropic glutamate receptor type 5; MPEP, 2-methyl-6-(phenylethynyl)pyridine; PI, propidium iodide; ART, antiretroviral therapy; ROS, reactive oxygen species; ER, endoplasmic reticulum; HFA, human fetal astrocytes; DMEM, Dulbecco's modified Eagle's medium; FBS, fetal bovine serum; BCA, bicinchoninic acid; PBS, phosphate-buffered saline

Received 23.5.16; revised 05.8.16; accepted 23.8.16; Edited by GM Fimia
} 
process, cytoplasmic organelles are sequestered within autophagosome and delivered into lysosomes to be degraded by acidic lysosomal hydrolases. Autophagy also functions as a housekeeping process that removes misfolded proteins and damaged organelles. In addition, autophagy pathway can sometimes be utilized by viruses to promote their own replication. ${ }^{26}$ Autophagy is initiated when stress signal is received from mammalian target of rapamycin (mTOR). mTOR activity is inhibited under stress condition, leading to activation of downstream pathway of autophagy-related proteins such as Atg1, Beclin-1, Atg5 and Atg7. The formation of autophagosome requires microtubule-associated protein-1 light chain 3 (MAPLC3), which is commonly used as the marker of autophagy.

Autophagy is generally considered to be a survival mechanism, which preserves the balance between protein synthesis, organelle biogenesis and their clearance. Autophagy has also been linked to non-apoptotic cell death, called type II programmed cell death, or autophagic cell death. ${ }^{27}$ Extensive autophagy has been reported when cells are exposed to various drugs of abuse. ${ }^{28-31}$ For example, our recent work has demonstrated that autophagy is associated with cocaineinduced astrocytic cell death. ${ }^{29}$ Similarly, autophagy has been detected when cells are exposed to low doses of METH, and suppression of the autophagy is associated with cell death. ${ }^{28,30}$ Autophagy has also been found to be involved in several neurodegenerative diseases such as Alzheimer's disease, Parkinson's disease and Huntington's disease. ${ }^{32-34}$ However, the role of autophagy in HIV-induced neurotoxicity is poorly understood. This study was designed to determine the combined effects of METH and gp120 on autophagy in astrocytes, and the underlying mechanism of the METH- and gp120-mediated autophagy.

\section{Results}

METH and gp120 IIlb induce autophagy in astrocytes. During autophagy, the cytosolic form of LC3 (LC3I) is conjugated to phosphotidylethanolamine to form LC3I-phosphotidylethanolamine complex (LC3II), which is widely accepted as the marker for autophagy activity. To determine whether METH and gp120 IIlb can induce autophagy in astrocytes, we treated SVGA astrocytes with varying concentrations of METH for $24 \mathrm{~h}$, followed by the western blot analysis of LC3II in whole-cell lysate. SVGA cells responded to METH treatment in a dose-dependent manner, with $1 \mathrm{mM}$ of METH showing maximum increase in LC3Il level ( 4-fold) (Figure 1a). SVGA cells were then treated with $1 \mathrm{mM}$ of METH for varying time periods. METH caused significant increase in LC3II level starting from $6 \mathrm{~h}$, and peaked at $24 \mathrm{~h}$ ( 6-fold) (Figure 1b). Similarly, to determine whether gp120 IIIb will induce autophagy in astrocyte, we treated cells with different concentrations of gp120 IIlb as indicated for $24 \mathrm{~h}$. The gp120 IIlb caused an increase in LC3II level in SVGA cells, with $400 \mathrm{pM}$ of gp120 IIlb showing maximum increase in LC3II ( 1.5-fold) (Figure 1c). Following that, to determine the optimal time point for gp120 IIlb-induced autophagy, we treated cells with $400 \mathrm{pM}$ of gp120 IIIb at varying time periods. Interestingly, gp120 IIlb caused initial increase in
LC3II level at $6 \mathrm{~h}$, and a subsequent decrease at $12 \mathrm{~h}$ followed by a peak at $24 \mathrm{~h}$ (1.6-fold) post-exposure (Figure 1d).

As METH and gp120 Illb individually induce autophagy in SVGA cells, we next examined whether they will show combination effect in inducing autophagy. We treated SVGA cells with $1 \mathrm{mM}$ of METH and $400 \mathrm{pM}$ of gp120 Illb individually and in combination. Surprisingly, METH and gp120 Illb together showed further increase in the level of LC3II ( 8-fold) compared with METH ( 4.5-fold) or gp120 IIlb (1.5-fold) alone (Figure 1e). To confirm this result, same treatment was applied to human primary astrocytes, which also yielded similar results (Figure 1f). As increased level of LC3II can be observed when autophagy is either induced or inhibited, a fusion inhibitor, bafilomycin A1, was used to exclude the possibility of defect in lysosomal degradation. Pretreatment of bafilomycin A1 caused further increase in the level of LC3II following METH and combination treatment (Figure 1g). The increase in autophagy level was further confirmed by immunocytochemistry in SVGA cells upon the treatment of METH and gp120 IIlb (Figure 1h). There was a substantial increase in LC3II-positive puncta when the cells were treated with METH and gp120 IIIb in combination compared with individual treatment. Furthermore, we examined the formation of autophagosomes by transmission electron microscopy in the SVGA (Figure 1i). The results showed numerous multi-membrane vacuoles (autophagosomes) in the combination treatment, whereas few or no autophagosomes were observed in the control, METH-, or gp120-treated cells. Taken together, these results clearly showed that METH and gp120 induce autophagy in astrocytes in additive manner.

Signaling proteins mTOR, Beclin-1, Atg5 and Atg7 are involved in METH- and gp120-induced autophagy in astrocytes. To determine the signaling molecules involved in METH- and gp120-induced autophagy, we treated SVGA cells with $1 \mathrm{mM}$ of METH, $400 \mathrm{pM}$ of gp120 Illb, and combination for $24 \mathrm{~h}$. mTOR is one of the upstream protein that has key role in initiation of autophagy. Activation of mTOR by phosphorylation suppresses autophagy, whereas its dephosphorylation leads to initiation of autophagy. Our results showed significant downregulation of p-mTOR level, when the SVGA cells were treated with METH and gp120 IIIb (Figure 2a). Beclin-1 is one of the most important proteins that initiate autophagosome formation. Our results showed that METH and gp120 IIlb significantly upregulate Beclin-1 level, suggesting the role of Beclin-1 in METH- and gp120mediated autophagy (Figure 2b). In addition, signaling molecules Atg5 and Atg7 have been reported to be involved in elongation of autophagosome. In METH- and gp120treated cells, both Atg5 and Atg7 were induced, suggesting the involvement of Atg5 and Atg7 in METH- and gp120induced autophagy in astrocytes (Figures $2 \mathrm{c}$ and $\mathrm{d}$ ).

To further investigate METH- and gp120-induced autophagic pathway, we treated cells with 3-methyladenine (3-MA), a phosphoinositide 3-kinase (PI3K) inhibitor. PI3KIII complexes with Beclin-1 and functions as one of the key regulators of autophagy. As shown in Figures 3a, 3-MA decreased the expression of METH- and gp120-induced LC3II. As expected, pretreatment of the cells with mTOR inhibitor rapamycin 
caused $>60 \%$ increase in the level of LC3II. Furthermore, to confirm the role of Beclin-1, Atg5 and Atg7 in METH- and gp120-induced autophagy, we used specific siRNAs of these proteins (Supplementary Figure 1, Figures 3b-d). Beclin-1
siRNA caused $\sim 50 \%$ reduction in the level of LC3II in METHor gp120 Illb-treated cells, whereas it caused $>70 \%$ reduction when the cells were treated with both METH and gp120Illb together. Similarly, Atg5 and Atg7 siRNAs reduced METH- and a
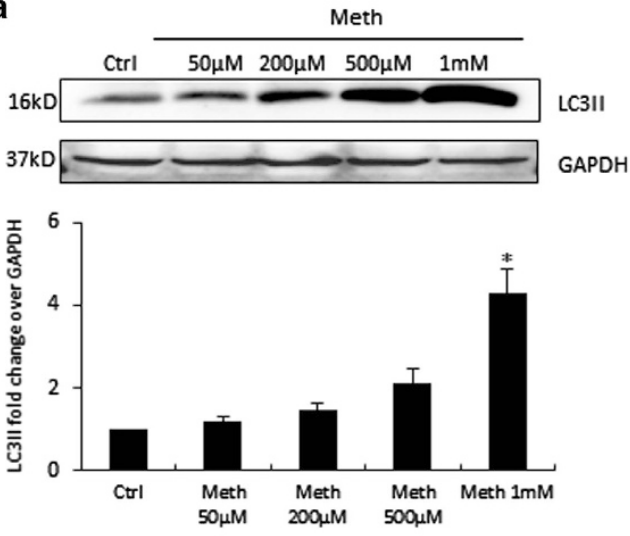

C
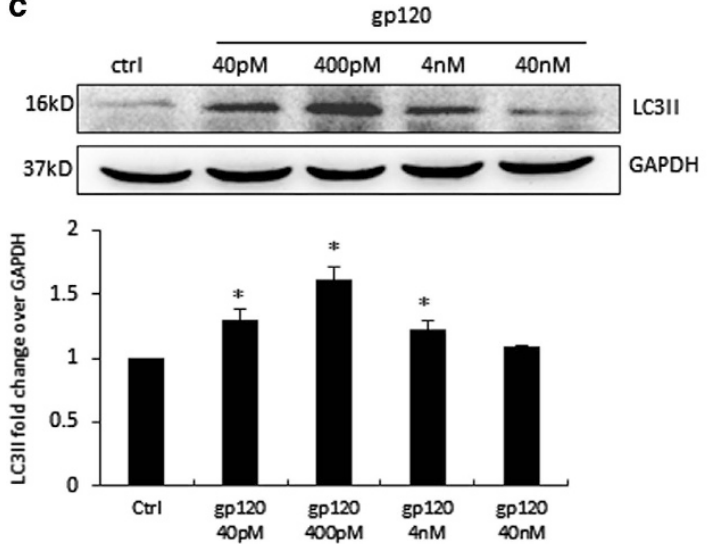

e
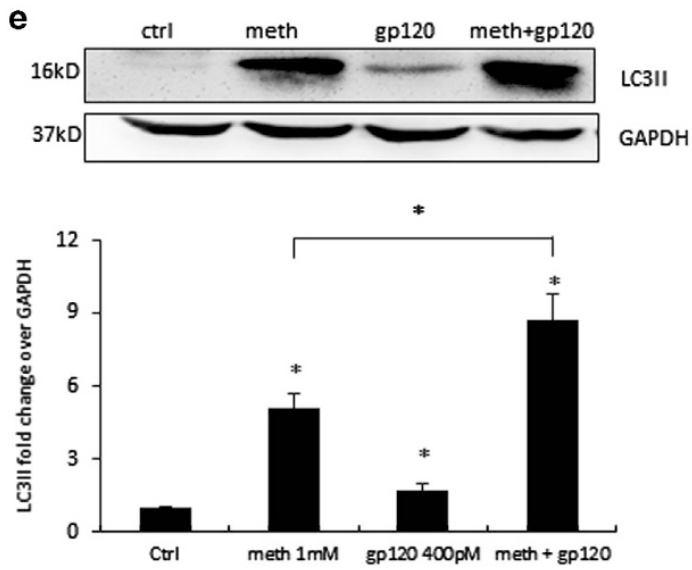

b
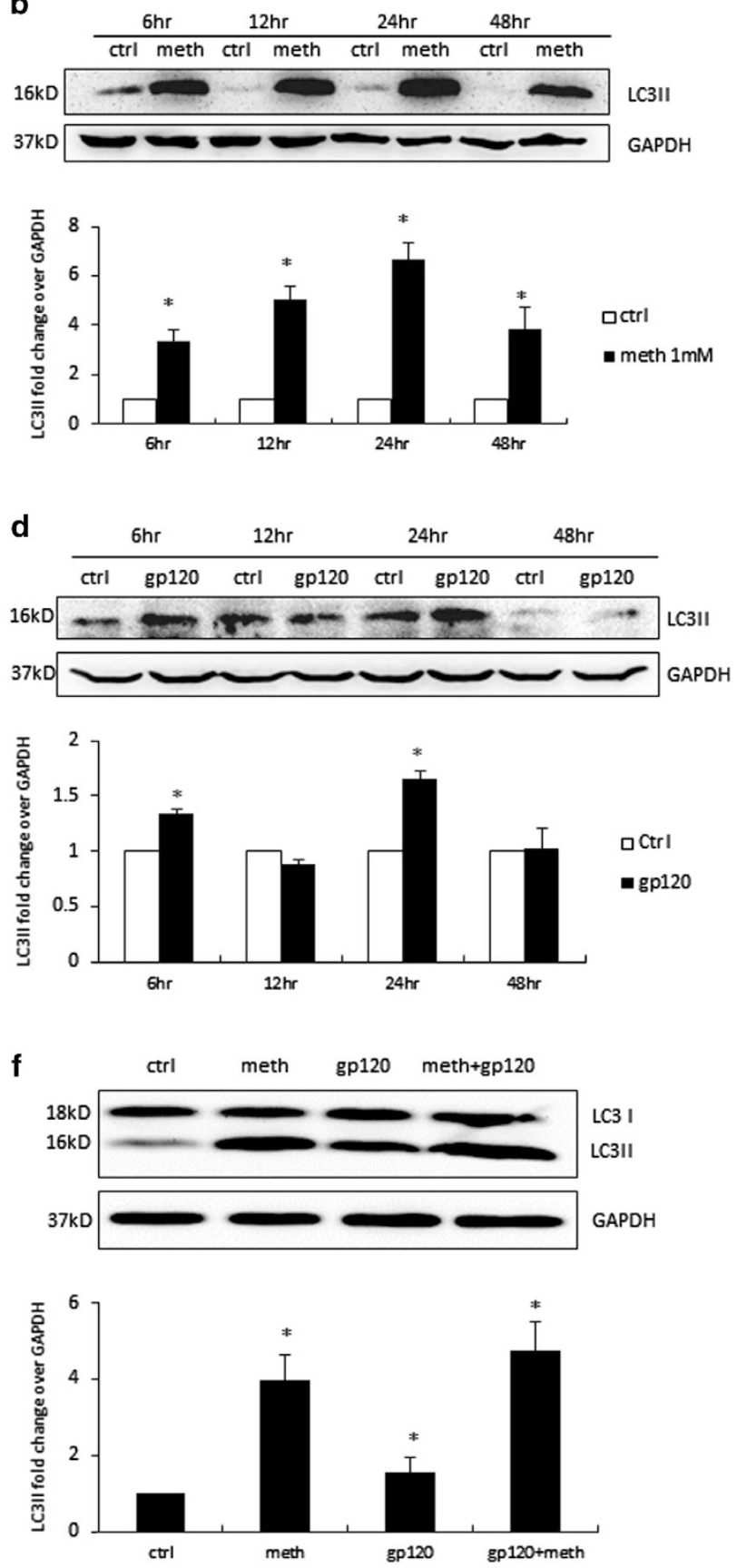

Figure $1 \mathrm{METH}$ and HIV-1 gp120 IIlb induce autophagy in astrocytes. LC3II was analyzed using the western blot and quantified by AlphaEase FC software (Alpha Innotech, San Leandro, CA, USA), which are shown at the bottom of each panel (a-f). Results are shown as mean \pm S.E. from three separate experiments. ${ }^{*} P<0.05$. (a) $S V G A$ cells were exposed to different doses of METH for $24 \mathrm{~h}$, (b) SVGA cells were exposed to $1 \mathrm{mM}$ of METH at varying time periods, (c) SVGA cells were exposed to different doses of HIV-1 gp120 Illb for $24 \mathrm{~h}$, (d) SVGA cells were exposed to $400 \mathrm{pM}$ gp120 Illb at varying time periods, (e) SVGA cells were exposed to $1 \mathrm{mM}$ of METH, $400 \mathrm{pM}$ of gp120 Illb, or both for $24 \mathrm{~h}$, (f) human primary astrocytes were treated with METH and gp120 Illb as indicated, (g) SVGA cells were exposed to bafilomycin A1 $1 \mathrm{~h}$ before treatment of METH, gp120 Illb, or both for $24 \mathrm{~h}$. (h) LC3ll punctate dots in METH- and gp120- treated SVGA cells. SVGA cells were treated with $1 \mathrm{mM}$ of METH, $400 \mathrm{pM}$ of gp120 Illb, or both for $24 \mathrm{~h}$. Cells were fixed with ice-cold methanol: acetone (1 : 1), immunostained with anti-LC3Il antibody, and examined by confocal microscopy (scale bar, $20 \mu \mathrm{m}$ ). (i) Electron microscopy images showing the ultrastructure of METH- and gp120-treated SVGA cells. Arrows in the electron micrograph denote presence of autophagosomes (scale bar, $2 \mu \mathrm{m})$. Immunostaining and microscopic images are representatives of at least three independent experiments 
g
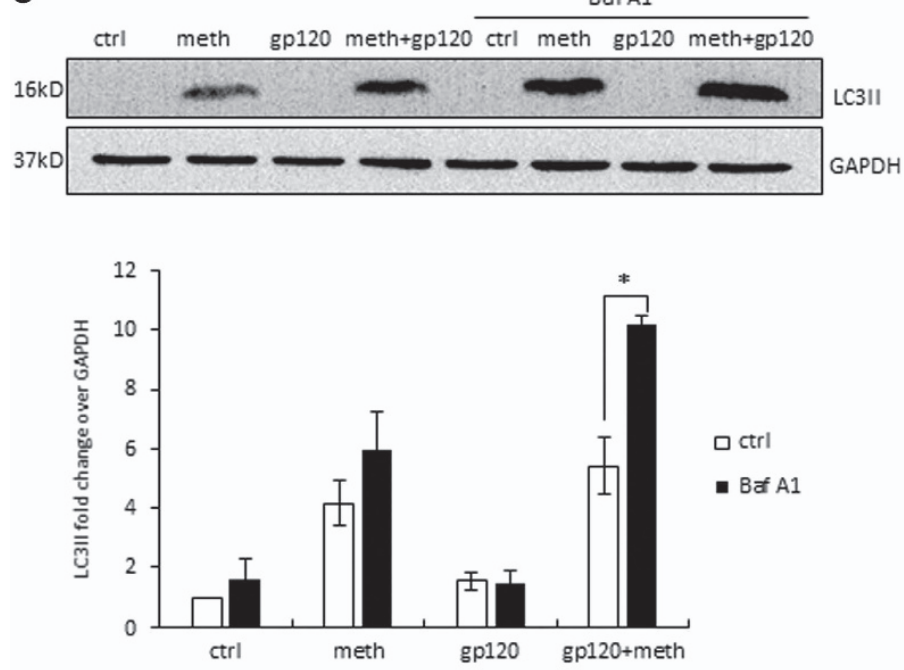

h

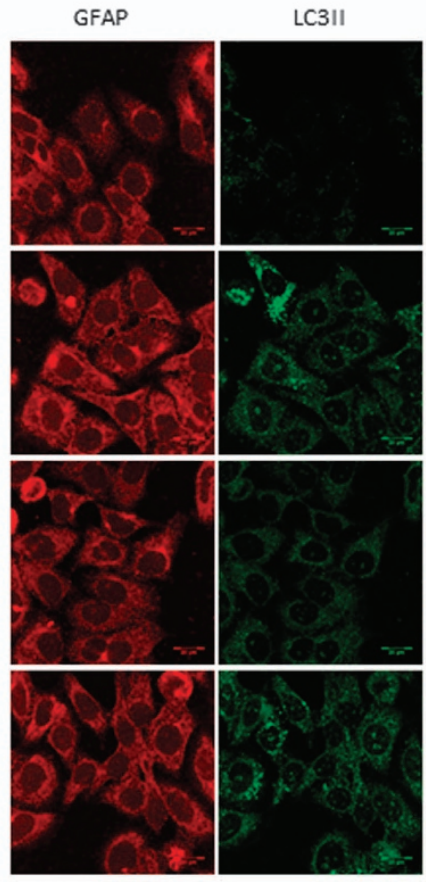

Merge

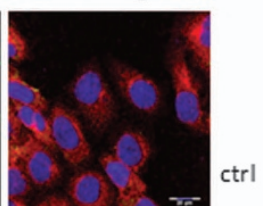

ctrl

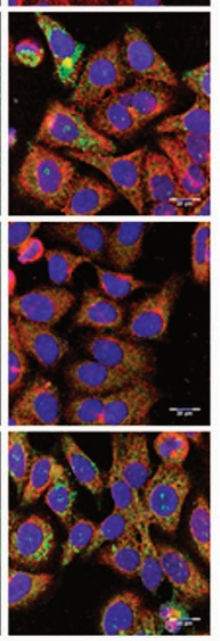

i
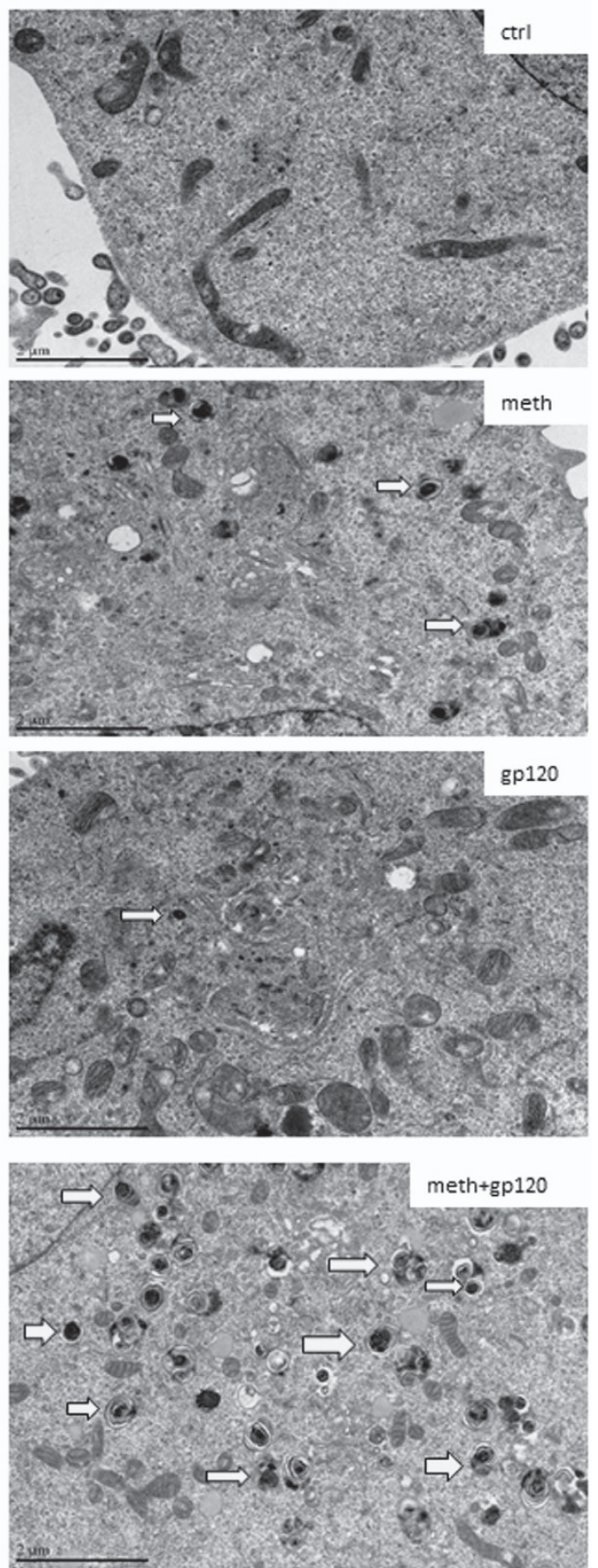

Figure 1 Continued

gp120-induced LC3II expression by $>60 \%$, whereas scrambled siRNA did not cause any significant change.

METH induces autophagy via opioid receptor and mGluR5 receptor-mediated pathway. Opioid receptor has been well documented in the literature for METH-mediated signaling that leads to neurotoxic effect. ${ }^{35,36,37}$ We therefore examined whether METH-induced autophagy was mediated by opioid receptor. Naltrexone is an antagonist that acts on multiple classes of opioid receptors, which shows most affinity to $\mu$-opioid receptor, and to a much less extent, the $\kappa$-opioid receptor and $\delta$-opioid receptor. To determine the effect of naltrexone on METH-induced autophagy, we treated SVGA cells with 10 or $100 \mu \mathrm{M}$ of naltrexone before METH treatment. Naltrexone blocked METH-induced LC3II expression with a significant decline in the LC3II level observed with $100 \mu \mathrm{M}$ of naltrexone treatment (Figure 4a). Another opioid receptor antagonist, nor-binaltorphimine dihydrochloride (nor-BNI), is highly selective for $k$-opioid receptor. Pretreatment of nor-BNI reduced METH-induced LC3II expression in a concentration-dependent manner, with $20 \mu \mathrm{M}$ showing $\sim 50 \%$ reduction in LC3II (Figure $4 b$ ). In addition to opioid 

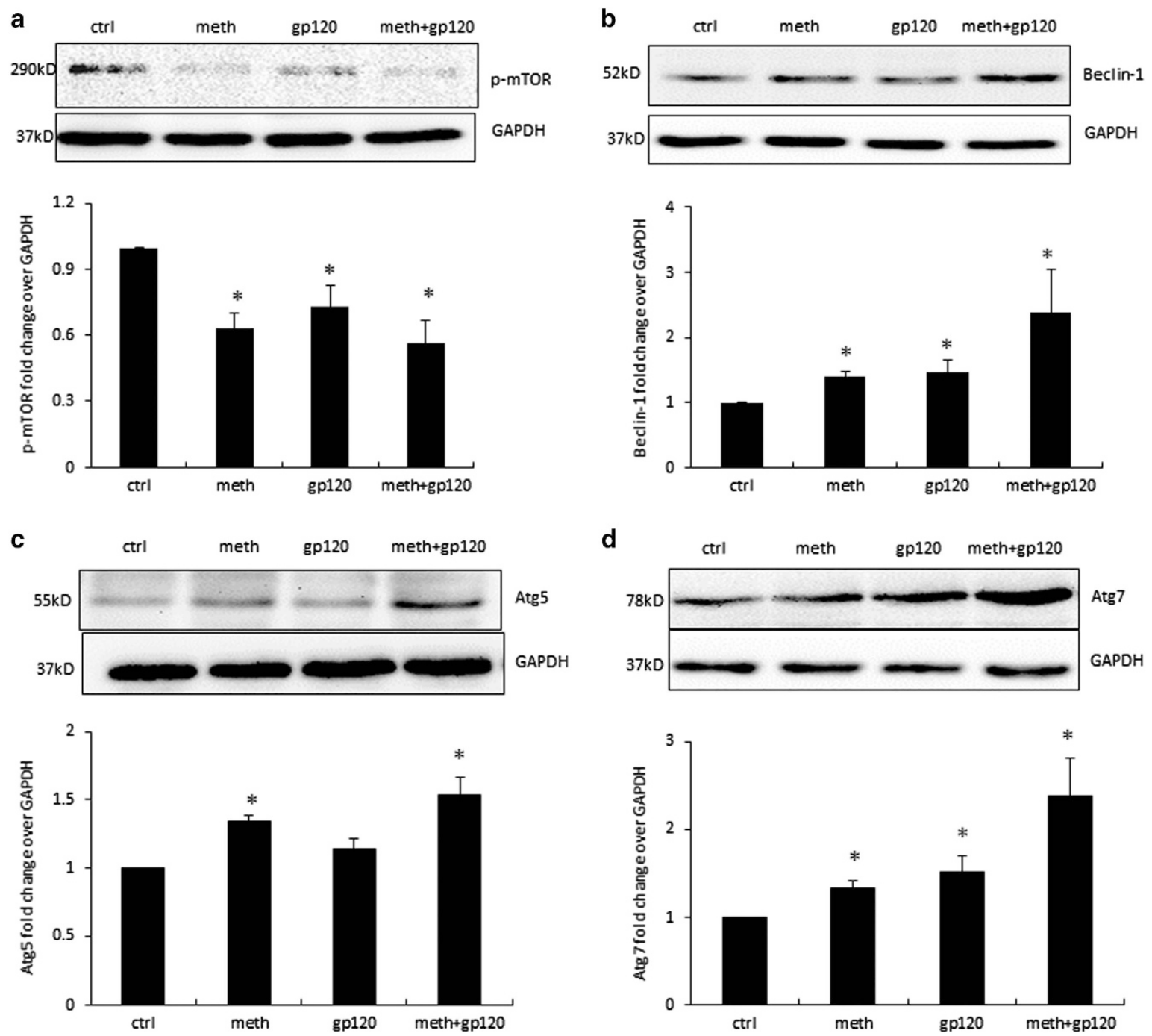

Figure 2 METH and gp120 Illb induce autophagy through mTOR, Beclin-1 and Atg5/7 pathways. SVGA cells were treated with $1 \mathrm{mM} \mathrm{METH}$ and $400 \mathrm{pM}$ gp120 IIIb for $24 \mathrm{~h}$ and were then subjected to western blotting to measure the signaling proteins p-mTOR (a), Beclin-1 (b), Atg5 (c) and Atg7 (d). The results are shown as mean \pm S.E. from three independent experiments. Data quantified by AlphaEase FC software are shown at the bottom of each panel. ${ }^{*} P<0.05$

receptors, metabotropic glutamate receptor type 5 (mGluR5) is considered to be associated with METH neurotoxicity. 2-Methyl-6-(phenylethynyl)pyridine (MPEP) at $20 \mu \mathrm{M}$ caused $55 \%$ reduction in METH-induced LC3II expression (Figure 4c). This result was further confirmed by immunocytochemistry in SVGA cells (Figures 4d and e). We also sought to determine whether combination of nor-BNI, naltrexone and MPEP would completely inhibit METHinduced autophagy. Our results showed that combination of the inhibitors did not cause any further reduction in LC3II level (Supplementary Figure 2). Therefore, our results suggest that METH may induce autophagy in astrocytes via alternative pathways.

After confirming the involvement of opioid and mGluR5 receptors, we next sought to investigate the involvement of the downstream signaling molecules of this pathway. The $\mathrm{PI}$ KK/Akt signaling pathway is upstream of mTOR, which is important for the regulation of autophagy. As shown in
Figures $4 \mathrm{f}-\mathrm{h}$, treatment of METH caused downregulation of phosphorylated-Akt level. When cells were treated with opioid inhibitors or mGluR5 inhibitors before METH treatment, the decrease in p-Akt level was partially attenuated. Furthermore, we found that METH and gp120 IIlb together caused further decrease in p-Akt level (Figure 4i). Combined with previous finding that METH treatment showed significant decrease in p-mTOR level (Figure 2a), these results suggest that METH and gp120 IIlb together induce autophagy by inhibiting Akt/mTOR pathway.

METH- and gp120-induced autophagy has pro-survival role against apoptotic cell death. Although autophagy is generally considered to be a protective mechanism, extensive autophagy can cause cell death, namely type II programmed cell death, or autophagic cell death. We therefore determined the role of autophagy in METH- and gp120treated astrocytes. In preliminary experiments, we found that 
a

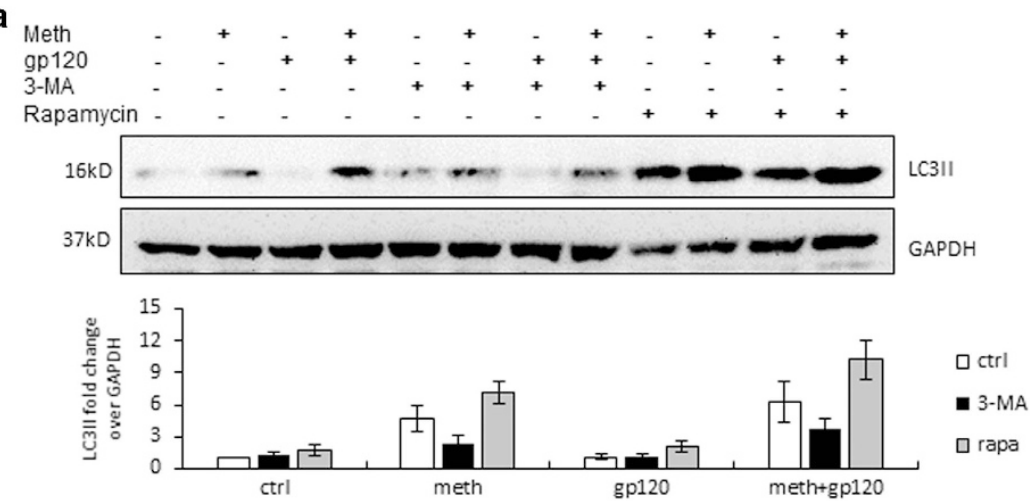

b
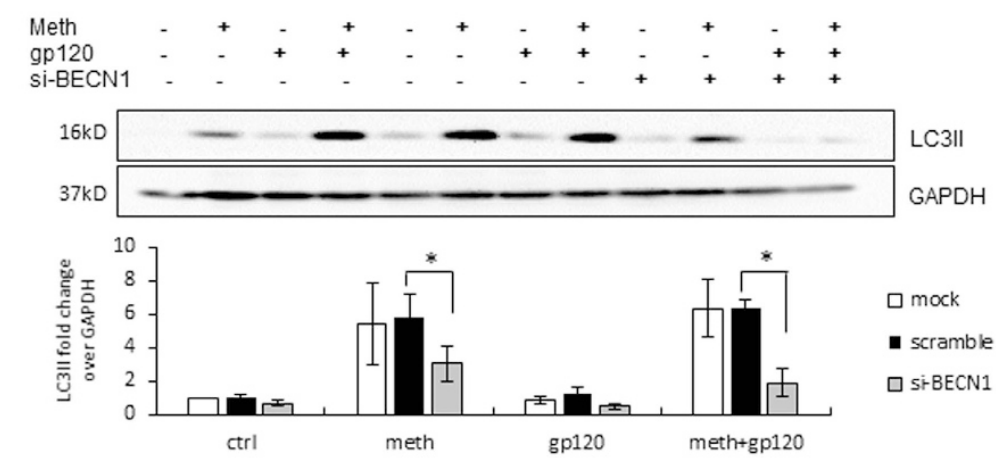

C
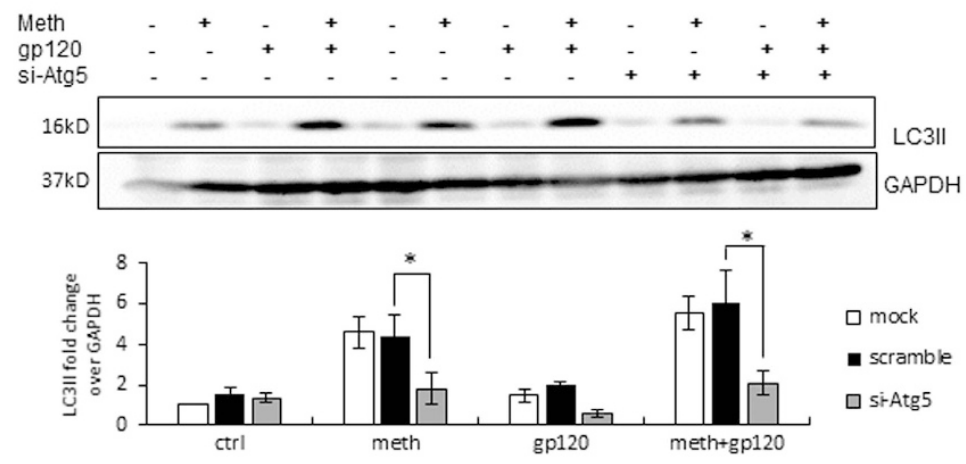

d
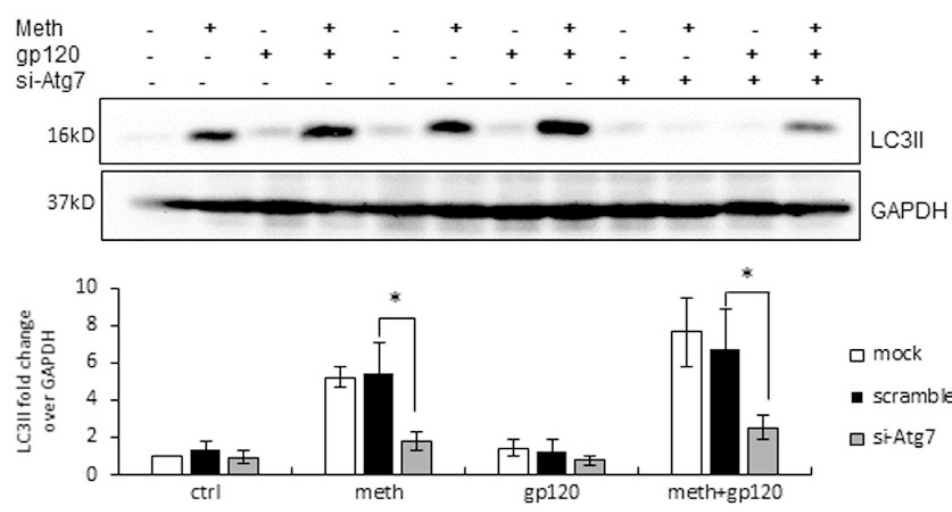

Figure 3 Involvement of signaling proteins mTOR, PI3K, Beclin-1, Atg5 and Atg7 as confirmed by the use of chemical inhibitors and specific siRNAs. The results are shown as mean \pm S.E. from three independent experiments. Data from the western blot of LC3II was quantified by AlphaEase FC software and are shown at the bottom of each panel. ${ }^{\star} P<0.05$. (a) SVGA cells were treated with or without 3-MA or rapamycin, and then treated with $1 \mathrm{mM} \mathrm{METH}$ and 400pM gp120 lllb for $24 \mathrm{~h}$. (b) SGVA cells transfected with Beclin-1 siRNA or a scrambled siRNA were treated with $1 \mathrm{mM}$ METH and 400pM gp120 Illb for $24 \mathrm{~h}$. (c) SGVA cells transfected with Atg5 siRNA or a scrambled siRNA were treated with $1 \mathrm{mM}$ of METH and 400pM of gp120 Illb for $24 \mathrm{~h}$. LC3ll was detected by western blot. (d) SGVA cells transfected with Atg7 siRNA or a scrambled siRNA were treated with $1 \mathrm{mM}$ of METH and $400 \mathrm{pM}$ of gp120 Illlb for $24 \mathrm{~h}$ 
a
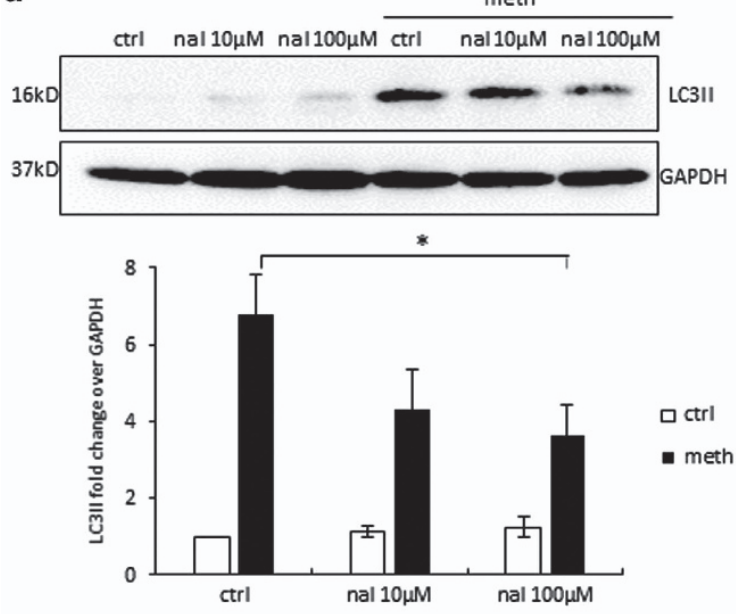

C
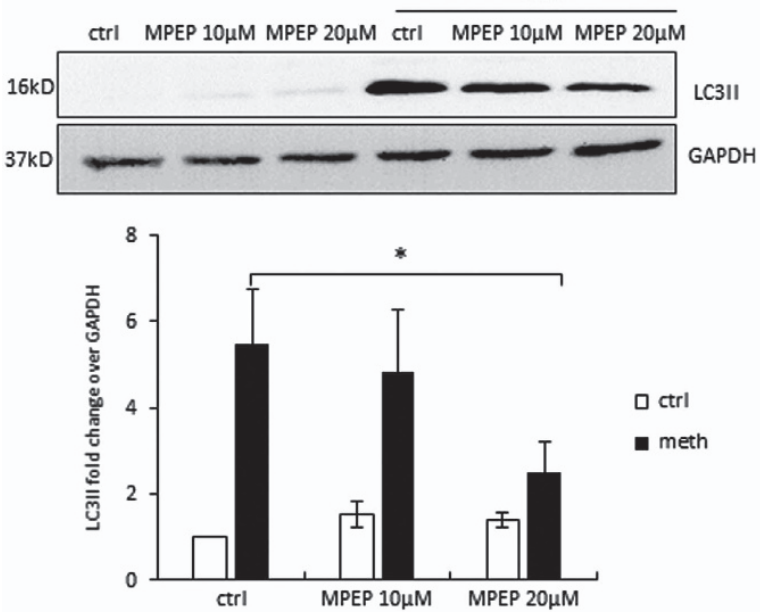

e

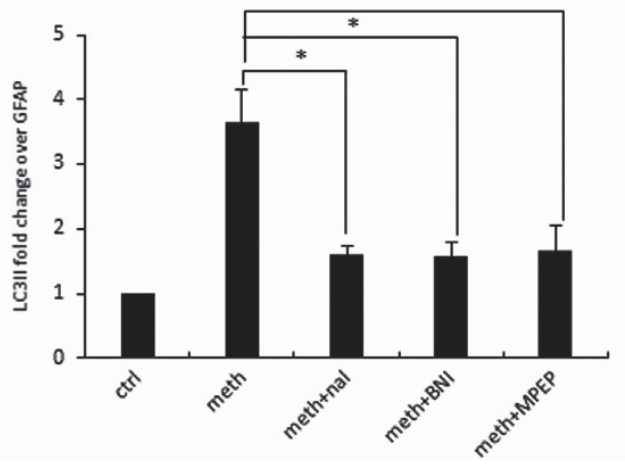

b
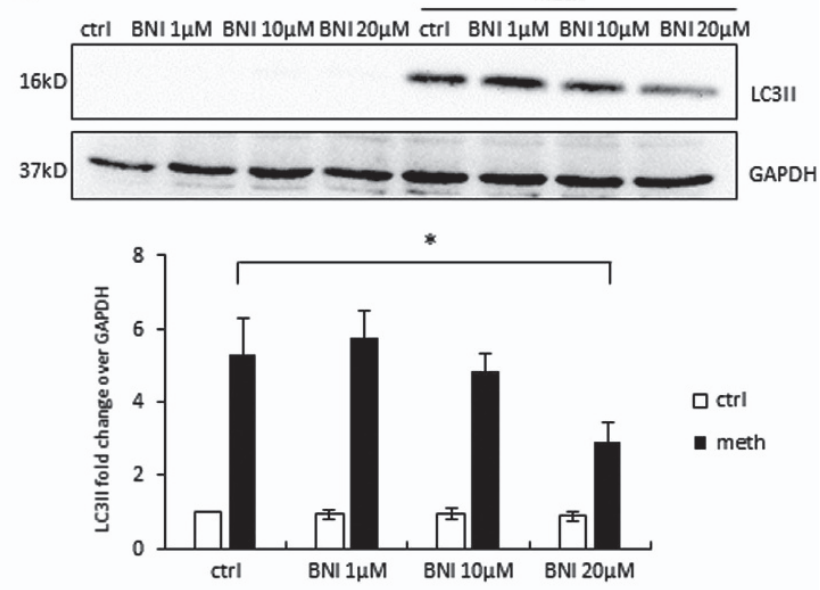

d

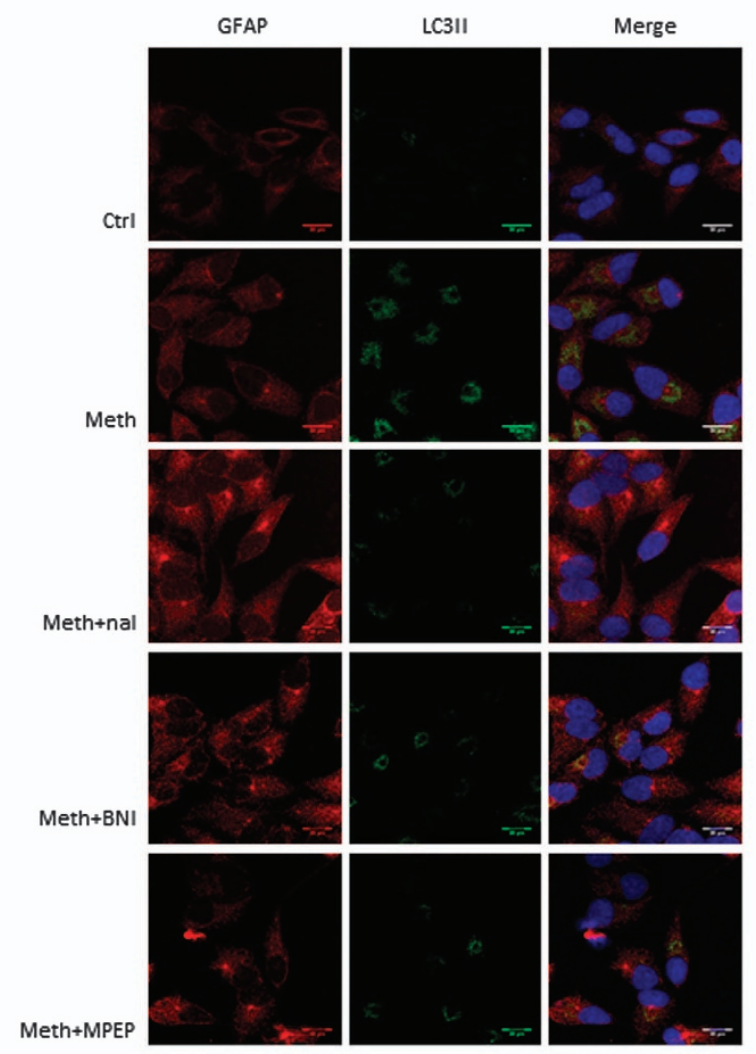

Figure 4 METH induces autophagy in astrocytes via opioid receptors and mGluR5 receptor. The results are shown as mean \pm S.E. from three independent experiments. Data from the western blot of LC3II (a-c) was quantified by AlphaEase FC software and are shown at the bottom of each panel. ${ }^{*} P<0.05$. For (f-i), cells were subject to western blot analysis with anti-Akt or anti-p-Akt antibody. (a) SVGA cells were treated with different concentrations of naltrexone, and then treated with $1 \mathrm{mM}$ METH for $24 \mathrm{~h}$. (b) SVGA cells were treated with different concentrations of nor-BNI, and then treated with $1 \mathrm{mM} \mathrm{METH}$ for $24 \mathrm{~h}$. (c) SVGA cells were treated with different concentrations of MPEP, and then treated with $1 \mathrm{mM}$ METH for $24 \mathrm{~h}$. (d) SVGA cells were treated with or without naltrexone, nor-BNI, and MPEP, and then treated with $1 \mathrm{mM}$ METH for $24 \mathrm{~h}$. LC3Il level was examined by confocal microscopy (scale bar, $20 \mu \mathrm{m}$ ). (e) Confocal microscopy data quantified by ImageJ software. (f) SVGA cells were treated with or without $100 \mu \mathrm{M}$ naltrexone, and then treated with $1 \mathrm{mM} \mathrm{METH}$ for $24 \mathrm{~h}$. (g) SVGA cells were treated with or without $20 \mu \mathrm{M}$ nor-BNI, and then treated with $1 \mathrm{mM}$ METH for $24 \mathrm{~h}$. (h) SVGA cells were treated with or without $20 \mu \mathrm{M}$ MPEP, and then treated with $1 \mathrm{mM} \mathrm{METH}$ for $24 \mathrm{~h}$. (i) SVGA cells were treated with $1 \mathrm{mM}$ METH and $400 \mathrm{pM}$ gp120 IIlb for $24 \mathrm{~h}$ 
f
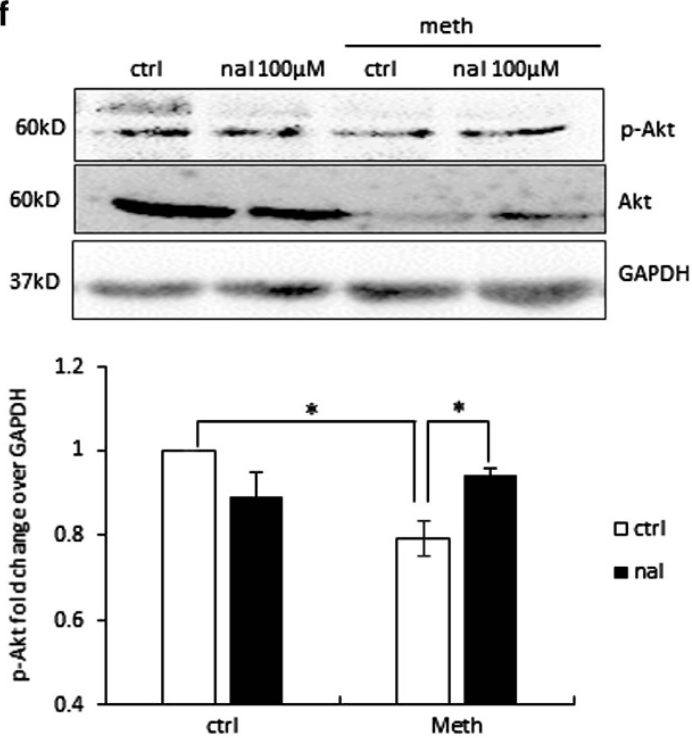

h
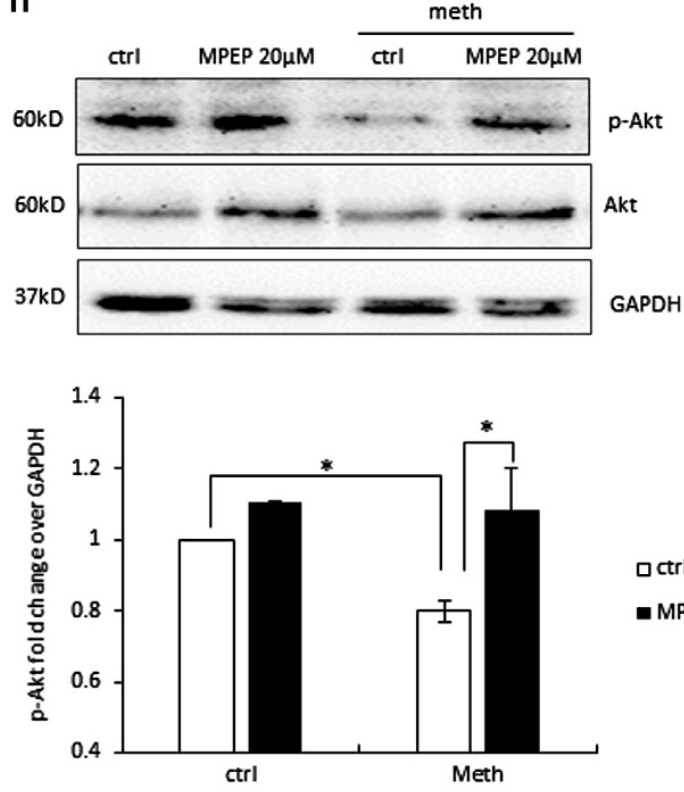

Figure 4 Continued
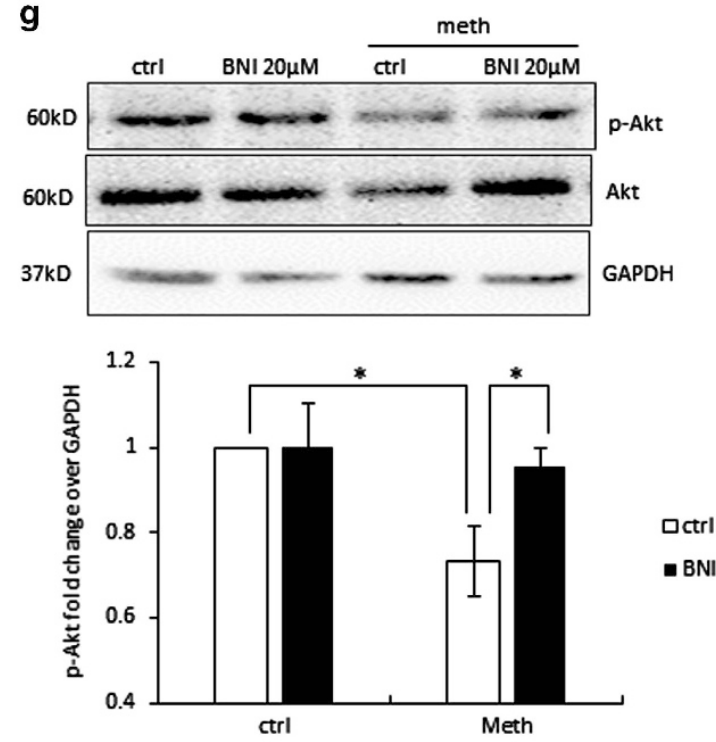

i
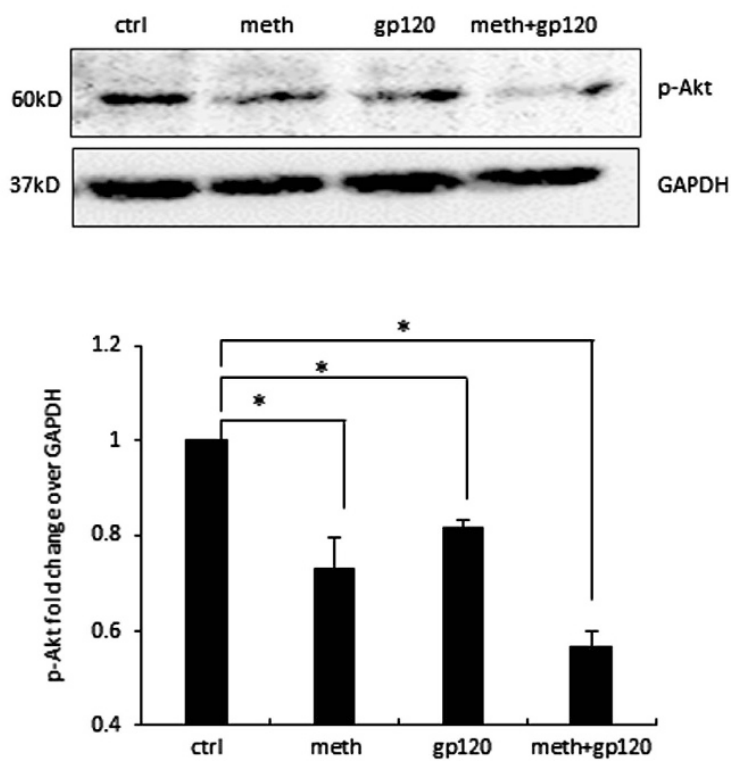

autophagy inhibitor, before each dose of METH or gp120 IIlb for $72 \mathrm{~h}$. The results showed that cell death induced by METH and gp120 was markedly increased by 3-MA treatment (Figure $5 \mathrm{c}$ and $\mathrm{d}$ ). These findings suggest that inhibition of autophagy can exacerbate METH- and gp120-induced cell death, which further reveals that autophagy is a pro-survival mechanism with a long-term exposure to METH and gp120.

\section{Discussion}

The use of METH is highly prevalent among individuals infected with HIV-1, especially men who have sex with men. ${ }^{38}$ Previous studies have shown that use of METH exacerbates HIV-1 infection, accelerates the onset of HAND and causes 
a

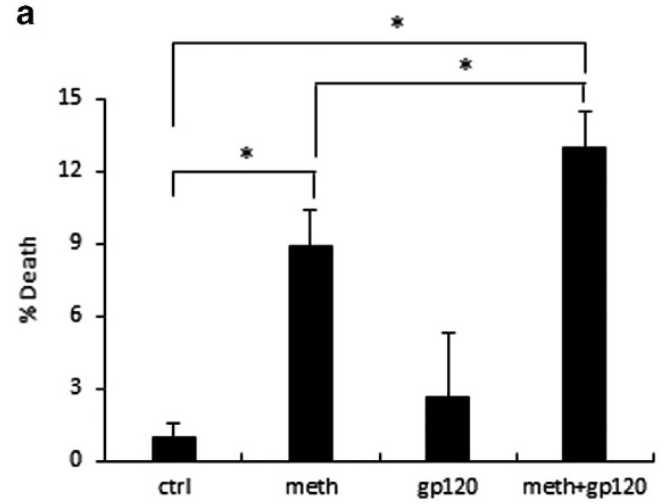

C

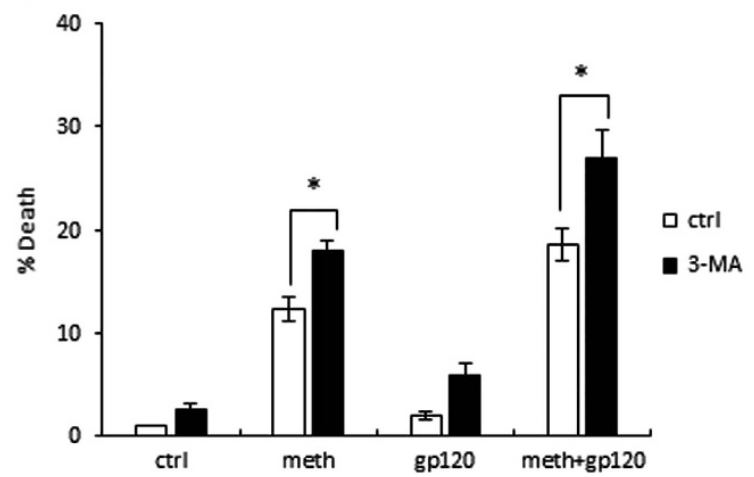

b

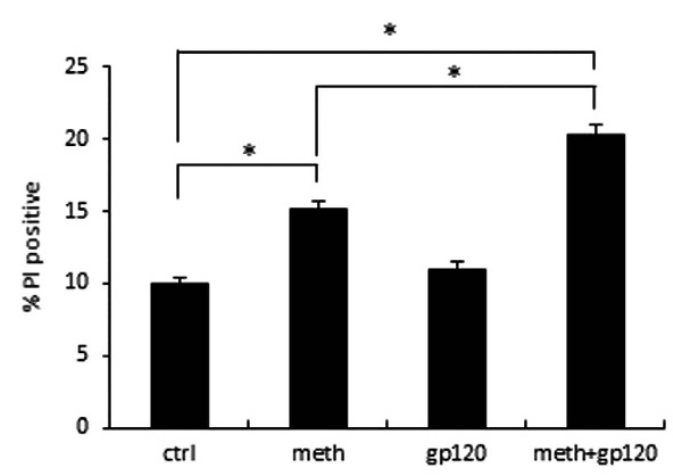

d

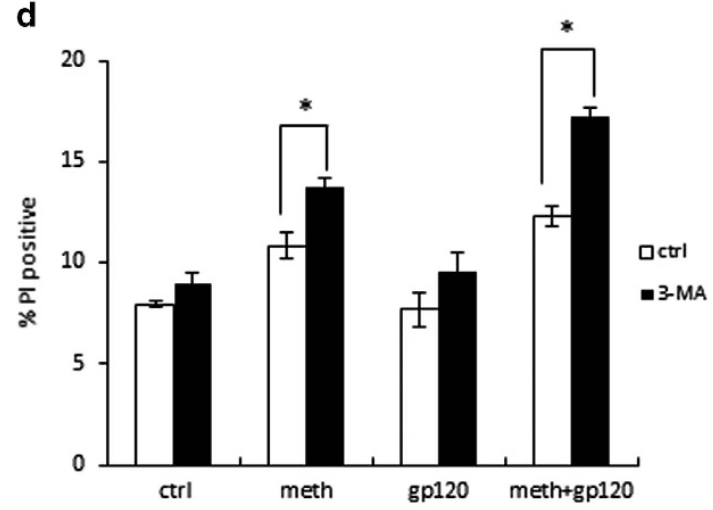

Figure 5 METH and gp120 Illb induce cell death, which is exacerbated when autophagy is inhibited. Results are shown as mean \pm S.E. from three separate experiments. ${ }^{*} P<0.05$. (a) SVGA cells were treated with $500 \mu \mathrm{M}$ METH and $400 \mathrm{pM}$ gp120 Illb every $24 \mathrm{~h}$ for $72 \mathrm{~h}$. The cells were subject to MTT assay. (b) SVGA cells were treated with $500 \mu \mathrm{M}$ METH and 400pM gp120 Illb every $24 \mathrm{~h}$ for $72 \mathrm{~h}$. The cells were subjected to PI staining. (c) SVGA cells were treated with 3-MA, and then treated with $500 \mu \mathrm{M}$ METH and $400 \mathrm{pM}$ gp120 IIlb every $24 \mathrm{~h}$ for $72 \mathrm{~h}$. The cells were subjected to MTT assay. (d) SVGA cells were treated with 3-MA, and then treated with $500 \mu \mathrm{M}$ METH and $400 \mathrm{pM}$ gp120 Illb every $24 \mathrm{~h}$ for $72 \mathrm{~h}$. Then cells were subject to PI staining

resistance to ART treatment. ${ }^{39}$ Several recent studies have shown synergistic induction of proinflammatory cytokines and oxidative stress by METH and HIV-1 gp120 that leads to CNS injury. ${ }^{23,24,40}$ However, the role of autophagy in METH- and gp120-induced neurotoxicity remains poorly understood. This study reveals for the first time that METH and HIV-1 gp120 show additive effect in inducing autophagy in astrocytes. METH exerts its effect through $k$ - and $\mu$-opioid receptors and mGluR5. METH and gp120 cause decrease in the level of downstream signaling protein Akt, thus inhibits mTOR and leads to the initiation of autophagy by regulating Beclin-1, Atg5 and Atg7 (Figure 6). This study also demonstrates that autophagy mitigates cell death induced by METH and gp120 in SVGA astrocytes. This is the first study that describes the complete mechanistic pathways involved in METH- and gp120-induced autophagy.

METH is self-administered, and typical doses for occasional users is $250-500 \mathrm{mg}$, and can reach as high as $1 \mathrm{~g}$ for chronic abusers. ${ }^{41}$ According to previous studies, $260 \mathrm{mg}-1 \mathrm{~g}$ of METH in binge users will produce $17-80 \mu \mathrm{M}$ blood METH concentrations. ${ }^{42}$ As METH is a small and lipid-soluble molecule, it is expected to distribute rapidly and extensively into high lipid-content tissues, such as brain. Therefore, the brain-to-serum concentration ratio in binge users can reach as high as $13: 1$, which means $200-1040 \mu \mathrm{M}$ of METH in the

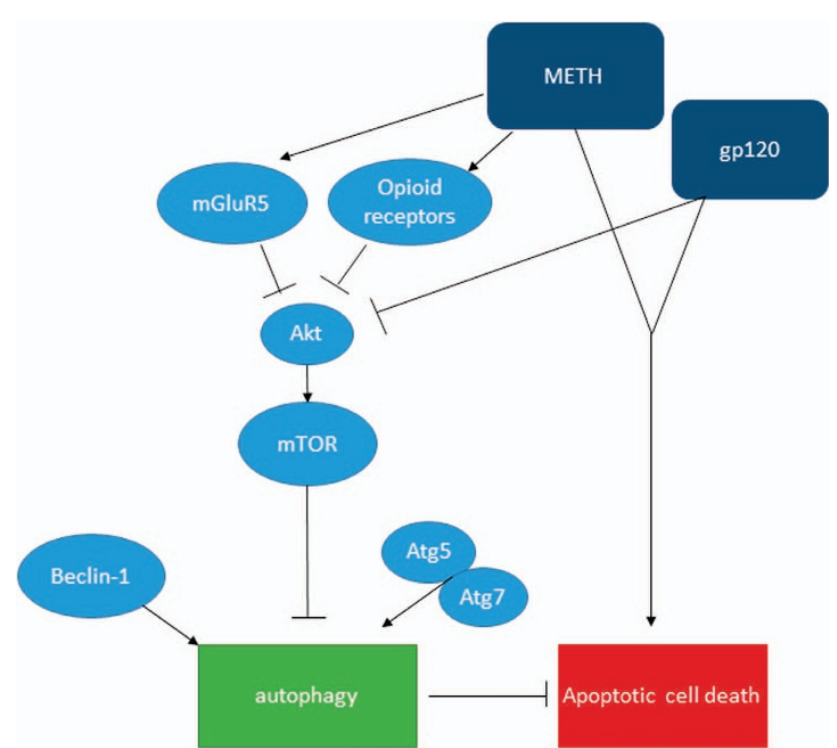

Figure 6 Schematic diagram showing the signaling pathways leading to METHand gp120-induced autophagy. METH interacts with mGluR5 and opioid receptors and induce autophagy. METH and gp120 inhibit Akt, which in turn suppresses downstream signal mTOR, and activates Beclin-1- and Atg5/7-dependent autophagy pathway. METH and gp120 coordinate to induce cell death, which is exacerbated when autophagy is inhibited 
brain of binge users. ${ }^{43}$ In terms of gp120 IIlb, the dose used in the study $(400 \mathrm{pM})$ matches well with the range of serum gp120 concentration measured in patients (100-800 pM). ${ }^{44}$ Therefore, the doses of both METH and gp120 IIlb used in this study are within physiological range and justifiable.

The development of addictive behavior of METH is regulated by mesolimbic dopaminergic system in the CNS. ${ }^{45,46}$ In addition, other neurotransmitter systems including GABAergic, glutamatergic, and opioidergic systems, are also thought to be involved in the modulation of the addictive behavior. ${ }^{47-49}$ Previous studies have demonstrated that interactions between opioid receptors and dopamine receptors have a critical role in the addictive effect of drugs of abuse. ${ }^{50}$ Of different subtypes of opioid receptors, $\mu$-opioid receptor has been shown to have modulatory role in METH-induced dopamine and serotonin metabolism in mice striatum. ${ }^{51}$ Pretreatment of naltrexone attenuated the expression of behavioral sensitization induced by METH in mice. ${ }^{52}$ Another opioid receptor, $k$-opioid receptor is known to be involved in the modulation of addictive behavior following administration of psychostimulants. ${ }^{53}$ Apart from opioid receptors, mGluR5 has been found to be associated with neurocognitive impairments mediated by METH. ${ }^{54-57}$ This study has demonstrated that both opioid receptors and mGluR5 interact with METH and initiate the downstream autophagy signaling cascade. As both opioid receptors and mGluRs are enriched in the CNS, it would be interesting to study the crosstalk between these receptors, and whether autophagy is associated with the behavioral modulating effects of drugs of abuse.

The kinase mTOR has a critical role in inducing autophagy. $\mathrm{PI}$ KK/Akt is a positive upstream regulator of $\mathrm{mTOR}$, and activation of mTOR suppresses autophagy. In this study, we have shown that both METH and gp120 IIlb lead to a decrease in the level of total and phosphorylated-Akt, and that METHinduced reduction in $\mathrm{p}$-Akt is abrogated by antagonists of both opioid receptors and mGluR5. Combining the fact that METH and gp120 cause downregulation of p-mTOR, it is reasonable to postulate that METH acts on both opioid receptor and mGluR5, and inhibits downstream signaling PI3K/Akt leading to deactivation of mTOR and initiation of autophagy. In addition, Beclin-1 and LC3 are the key proteins for normal function of autophagy. During autophagy, LC3I is converted to LC3II, which localizes on the surface of autophagosome. There is difference in the immunoreactivity of LC3I and LC3II, and the sensitivity of detection is much higher for LC3II than that for LC3I in most cases. Therefore, the comparison of LC3II level between different treatment groups is considered to be a more accurate method. ${ }^{58}$ Beclin-1 is essential for the formation of autophagosome, and has a crucial role in the maintenance of homeostasis and cellular housekeeping. The pro-autophagic activity of Beclin-1 can be attenuated by $\mathrm{Bcl}-2,{ }^{59}$ and therefore, Beclin-1-Bcl-2 complex is thought to regulate the switch between autophagy and apoptosis. ${ }^{60}$ Our results showed that METH and gp120 cause increase the level of Beclin-1 in astrocytes, and knockdown of Beclin-1 significantly abrogated the change in LC3II level, suggesting the critical role of Beclin-1. As METH and gp120 contribute to astrocytic cell death, future study will focus on the interaction between Bcl-2 and Beclin-1 in determining the fate of cells under the stress of drugs of abuse.
There has long been a debate on the role of autophagy. It has been documented as a pro-survival mechanism for the cells that helps to maintain the nutrients level under starvation condition. ${ }^{25}$ However, there is conflicting evidence indicating that autophagy could be a pro-death mechanism. ${ }^{61-64}$ Autophagic cell death was first defined morphologically for the cell death that shows appearance of numerous double-membrane vacuoles in the cytoplasm. ${ }^{27}$ However, one question that constantly arises is whether autophagy activity monitored in the dying cells is the cause of death or is the attempt to salvage the cells from other forms of cell death. In terms of drugs of abuse, it has been reported that suppression of autophagy precipitates neuronal cell death following low doses of METH treatment. ${ }^{30}$ Chronic treatment of morphine, has shown to induce cell death, which is further exacerbated by autophagy inhibition. ${ }^{31}$ In our study, there is $\sim 5 \%$ cell death following 3 day METH treatment. Although gp120 alone does not cause any significant change in cell viability, it significantly promotes cell death when treated in combination with METH. In this case, the cell death is exacerbated when autophagy is blocked, suggesting that autophagy is an early response to the stress induced by METH and gp120, and has a protective role in this scenario.

Autophagy, besides a pro-survival mechanism against environmental stress, is also considered to be a defensive mechanism against invasion of microorganisms in innate and adaptive immunity. ${ }^{25}$ It has been reported that autophagosomes target and degrade a wide range of intracellular pathogens. ${ }^{65-67}$ Increasingly evident is that autophagy contributes to HIV-1 replication and progression. ${ }^{68}$ Some of the autophagy-associated genes have been correlated with HIV-1 replication as well. For example, shRNA knockdown of Atg4A, Atg5 and Atg16 has been shown to inhibit replication of HIV-1 LA1 in SupT1 cells, without affecting cell viability. ${ }^{69}$ In another study, LC3 and Beclin-1 are found in complexes with HIV Gag and Nef, in which, Nef acts against the maturation of autophagosome and protects HIV from being degraded. ${ }^{70}$ In terms of HIV-associated neurologic diseases, increased autophagic markers were found in the brain tissues of patients with HIV-encephalitis and HAD. $^{71,72}$ As HIV-1 gp120 is found to induce autophagy, further study to visualize the localization of this viral protein would confirm the function of gp120 in autophagy initiation and maturation.

METH has been found to exacerbate HIV-induced cytotoxicity in many aspects. ${ }^{24,73} \mathrm{METH}$ and gp120 are known to cause oxidative stress, which takes place via altered expression of CYP450 and multidrug resistance protein-1. ${ }^{24,74}$ In addition, oxidative stress has also been proved to have a role in the development of HAND. ${ }^{75}$ Previous reports have demonstrated that reactive oxygen species (ROS) generated in mitochondria represents one of the main inducers of autophagy. ${ }^{76}$ In response to ROS, preferential autophagy can occur, which clears damaged or excess organelles such as peroxisomes, ${ }^{77}$ endoplasmic reticulum $(E R)^{78}$ and mitochondria. $^{79}$ Other than that, oxidized proteins can be degraded by autophagy as well. ${ }^{80}$ In these cases, autophagy functions as a defense mechanism against oxidative stress. Therefore, it would be interesting to investigate the role of ROS in METH- and gp120-induced autophagy in astrocytes. 
In summary, this study shows that METH and HIV-1 gp120 additively induce autophagy in astrocytes, and Akt, mTOR, Beclin-1, Atg5 and Atg7 are involved in the autophagic signaling pathway. Our study further suggests that combination treatment of METH and gp120 cause cell death, which is further exacerbated by autophagy inhibition. The study is clinically relevant because METH is highly prevalent in HIV-1 patients and METH is known to exacerbate HIV neuropathogenesis. Our study aids to the knowledge in HIV-1-associated neurotoxicity and a new direction for further study.

\section{Materials and Methods}

Cell culture and reagents. SVGA cells (astroglial cells modified from simian virus 40 (SV40)-transformed human glial cells (SVG)) were generously provided by Dr. Avindra Nath. Cells were grown in Dulbecco's modified Eagle's medium (DMEM) (Cellgro, Manassas, VA, USA) supplemented with 10\% head-inactivated fetal bovine serum (FBS), 1\% non-essential amino acids, 1\% sodium bicarbonate, $1 \%$ L-glutamine and $50 \mu \mathrm{g} / \mathrm{ml}$ of gentamicin. Human fetal astrocytes (HFA) were obtained from aborted fetal brain tissue from Birth Defect Research Laboratory (BDRL), Seattle, WA, USA. HFA were grown in DMEM media supplemented with $10 \%$ FBS and $1 \%$ gentamicin. The cells were maintained in an incubator at $37{ }^{\circ} \mathrm{C}$ and humidified air with $5 \% \mathrm{CO}_{2}$. The cells were seeded in six-well plates at a density of $0.8 \times 10^{6}$ per well in $2 \mathrm{ml}$ media and allowed to adhere overnight before treatment with METH and gp120 Illb as specified in the figures. METH, PI, naltrexone and mGluR5 antagonist MPEP were obtained from Sigma-Aldrich (St. Louis, MO, USA). Recombinant HIV-1 gp120 Illb (catalog number 11784) was obtained from the NIH AIDS Research and Reference Reagent Program. KOR antagonist nor-BNI was purchased from Tocris Bioscience (Ellisville, MO, USA). RIPA buffer was purchased from Boston BioProducts, Ashland, MA, USA (catalog number BP-115DG). Lipofectamine 2000 was purchased from Invitrogen Inc. (Carlsbad, CA, USA). The inhibitors against PI3K (3-MA) and mTOR (rapamycin) were obtained from Cayman Chemicals (Ann Arbor, MI, USA). Specific antibodies against LC3B, Atg5, Atg7, p-Akt, p-Bcl-2, p-mTOR and GAPDH were obtained from Cell Signaling Technology (Beverly, MA, USA). Vectashield Mounting Medium with DAPI was obtained from Vector laboratories (Burlingame, CA, USA). MTT assay kit was obtained from EMD Millipore (Billerica, MA, USA). Specific siRNAs of Beclin-1, Atg5 and Atg7, and control siRNA were purchased from Ambion Inc. (Carlsbad, CA, USA).

Transfection of astrocytes with siRNA. Cells were plated at $0.6 \times 10^{6}$ cells per well in a six-well plate. The cells were allowed to adhere overnight before transfection with $50 \mathrm{nM}$ siRNA. Transfection of SVGA was performed using Lipofectamine 2000 as per the manufacturer's instructions. Briefly, complete medium was removed from plates, and cells were washed twice with phosphatebuffered saline (PBS) before addition of serum-free medium. Transfection reagent as mixtures of Opti-MEM, lipofectamine and siRNAs against Beclin-1, Atg5, Atg7 and control siRNA were prepared and added into the wells. After $24 \mathrm{~h}$, the transfection reagent was replaced with fresh complete medium. Cells were trypsinized after $10 \mathrm{~h}$ and re-seeded into six-well plates at a density of $0.8 \times 10^{6}$ per well. METH and gp120 Illb treatments were performed the next day as described above. Transfection with $50 \mathrm{nM}$ of scrambled siRNA was used as the negative control.

Western blotting. SVGA cells were harvested at indicated time points in RIPA buffer (Boston BioProducts). The whole-cell lysates were homogenized and centrifuged for $15 \mathrm{~min}$ at 14000 r.p.m. to obtain protein extracts. The protein concentration was measured using bicinchoninic acid (BCA) assay. In all, $40 \mu \mathrm{g}$ of protein was loaded in each well of $12 \%$ polyacrylamide gel for electrophoresis. The proteins were separated at $90 \mathrm{~V}$ for $2.5 \mathrm{~h}$ and transferred onto PVDF membrane at $350 \mathrm{~mA}$ for $90 \mathrm{~min}$. The membranes were probed with appropriate primary and secondary antibodies for LC3ll, Beclin-1, P-Bcl-2, p-mTOR, p-Akt, Atg5 and Atg7 to measure their expression levels. The bands were detected using BM Chemiluminescence Western Blotting Substrate (POD) (Roche Applied Sciences, Indianapolis, IN, USA). The bands were analyzed using AlphaEase FC software (Alpha Innotech, San Leandro, CA, USA), and the intensities of bands were normalized using GAPDH.
Immunocytochemistry. SVGA cells were seeded at $0.8 \times 10^{6}$ on $1.5 \mathrm{~mm}$ cover slips followed by treatment with METH and gp120 IIllb. After termination of the treatment, the cells were fixed with $1: 1$ ice-cold methanol and acetone solution for $20 \mathrm{~min}$ at $-20{ }^{\circ} \mathrm{C}$. The wells were air dried followed by blocked and permeabilized with $1 \%$ BSA in PBS with $0.1 \%$ Triton for 30 min. After blocking, the cells were then incubated with a cocktail of rabbit anti-LC3B antibody $(1: 2000)$ and a mouse antiGFAP antibody (1: 1500) (Abcam, Cambridge, MA, USA) overnight in a humidified chamber. After three washes with $0.1 \%$ Triton in PBS, the cells were incubated in the dark chamber for $1 \mathrm{~h}$ with an anti-mouse antibody conjugated with Alexa Fluor $555(1: 2000)$ and an anti-rabbit antibody conjugated with Alexa Fluor 488 $(1: 2000)$ (Cell Signaling Technology) followed by three washes with $0.1 \%$ Triton in PBS. Finally, the cover slips were transferred onto glass slides with $10 \mu \mathrm{l}$ of Vectashield mounting reagent with DAPI. The microscopy analysis was performed using a Leica TCS SP5 II laser scanning confocal microscope. The images were captured using a 40X zoom lens and, ImageJ software was used to analyze the images and calculate the intensity. GFAP was used as housekeeping protein to normalize the intensity of the LC3II.

Transmission electron microscopy. SVGA cells were treated with METH and gp120 $\mathrm{lllb}$ as indicated, and fixed in $2.5 \%$ glutaraldehyde in $0.1 \mathrm{M}$ sodium cacodylade buffer at $4{ }^{\circ} \mathrm{C}$ for overnight. Specimens were processed and observed under transmission electron microscopy in Electron Microscopy Laboratory in School of Dentistry, UMKC.

Cell proliferation assay. Cells were plated in 12-well plates and treated with METH and gp120 Illb for indicated time periods. Upon termination of the experiment, medium was removed, and cells were washed with PBS. Cells were incubated with $500 \mu \mathrm{l}$ of $0.2 \mathrm{mg} / \mathrm{ml}$ MTT solution at $37^{\circ} \mathrm{C}$ for $3 \mathrm{~h}$. The supernatants were discarded and $500 \mu \mathrm{l}$ per well dimethyl sulfoxide was added. MTT assay was performed to measure cell viability using a microplate reader. Absorbance was obtained at $570 \mathrm{~nm}$ with a reference filter at $630 \mathrm{~nm}$.

Detection of cell death by PI staining. Cells were plated in 12-well plates and treated with METH and gp120 lllb for indicated time periods. Upon termination of the experiment, cells were washed twice with PBS, digested with trypsin-EDTA solution and collected by centrifugation. Cells were further washed twice with icecold PBS, and incubated with $500 \mu \mathrm{l}$ of $0.8 \mu \mathrm{g} / \mathrm{ml} \mathrm{PI}$. Flow cytometric analysis was performed to monitor the florescence of DNA-bound PI. All data were analyzed by BD FACSDiva software (BD Biosciences, San Jose, CA, USA).

Statistical analysis. The statistical analysis was performed to represent the data in mean \pm S.E. values. Results were based on at least three independent experiments with individual experiments performed in triplicate. For the comparison between two groups, statistical analysis was performed using one-way ANOVA to calculate $P$-values, and $P$-value $\leqslant 0.05$ was considered statistically significant.

\section{Conflict of Interest}

The authors declare no conflict of interest.

Acknowledgements. We acknowledge the use of the confocal microscope in the University Missouri, Kansas City School of Dentistry Confocal Microscopy Core. This facility is supported by the UMKC Office of Research Services, UMKC Center of Excellence in Dental and Musculoskeletal Tissues, and NIH grant S10RR027668. We also thank Dr. Mary Walker to allow us use of EM core. This work was supported by grants from National Institute on Drug Abuse (DA025528) and National Institute on Alcohol Abuse and Alcoholism (AA020806) to AK.

1. Mothobi NZ, Brew BJ. Neurocognitive dysfunction in the highly active antiretroviral therapy era. Curr Opin Infect Dis 2012; 25: 4-9.

2. Rumbaugh JA, Steiner J, Sacktor N, Nath A. Developing neuroprotective strategies for treatment of HIV-associated neurocognitive dysfunction. Futur HIV Ther 2008; 2: 271-280.

3. Ton $\mathrm{H}$, Xiong H. Astrocyte dysfunctions and HIV-1 neurotoxicity. J AIDS Clin Res 2013; 4: 255

4. Thompson KA, McArthur JC, Wesselingh SL. Correlation between neurological progression and astrocyte apoptosis in HIV-associated dementia. Ann Neurol 2001; 49: 745-752.

5. Nath A. Human immunodeficiency virus (HIV) proteins in neuropathogenesis of HIV dementia. J Infect Dis 2002; 186(Suppl 2): S193-S198. 
6. Shah A, Kumar A. HIV-1 gp120-mediated increases in IL-8 production in astrocytes are mediated through the NF-kappaB pathway and can be silenced by gp120-specific siRNA. $J$ Neuroinflammation 2010; 7: 96.

7. Shah A, Singh DP, Buch S, Kumar A. HIV-1 envelope protein gp120 up regulates CCL5 production in astrocytes which can be circumvented by inhibitors of NF-kappaB pathway. Biochem Biophys Res Commun 2011; 414: 112-117.

8. Shah A, Vaidya NK, Bhat HK, Kumar A. HIV-1 gp120 induces type-1 programmed cell death through ER stress employing IRE1alpha, JNK and AP-1 pathway. Sci Rep 2016; 6: 18929

9. Shah A, Verma AS, Patel KH, Noel R, Rivera-Amill V, Silverstein PS et al. HIV-1 gp120 induces expression of IL-6 through a nuclear factor-kappa B-dependent mechanism: suppression by gp120 specific small interfering RNA. PLoS One 2011; 6: e21261.

10. Nookala AR, Kumar A. Molecular mechanisms involved in HIV-1 Tat-mediated induction of IL-6 and IL-8 in astrocytes. J Neuroinflammation 2014; 11: 214.

11. Nookala AR, Shah A, Noel RJ, Kumar A. HIV-1 Tat-mediated induction of CCL5 in astrocytes involves NF-kappaB, AP-1, C/EBPalpha and C/EBPgamma transcription factors and JAK, PI3K/Akt and p38 MAPK signaling pathways. PLOS One 2013; 8: e78855.

12. Liu X, Kumar A. Differential signaling mechanism for HIV-1 Nef-mediated production of IL-6 and IL-8 in human astrocytes. Sci Rep 2015; 5: 9867.

13. Liu X, Shah A, Gangwani MR, Silverstein PS, Fu M, Kumar A. HIV-1 Nef induces CCL5 production in astrocytes through p38-MAPK and PI3K/Akt pathway and utilizes NF-kB, CEBP and AP-1 transcription factors. Sci Rep 2014; 4: 4450.

14. Gangwani MR, Kumar A. Multiple protein kinases via activation of transcription factors NF-kappaB, AP-1 and C/EBP-delta regulate the IL-6/L-8 production by HIV-1 Vpr in astrocytes. PLoS One 2015; 10: e0135633.

15. Borgmann K, Ghorpade A. HIV-1, methamphetamine and astrocytes at neuroinflammatory crossroads. Front Microbiol 2015; 6: 1143.

16. Fumagalli $F$, Gainetdinov RR, Valenzano KJ, Caron MG. Role of dopamine transporter in methamphetamine-induced neurotoxicity: evidence from mice lacking the transporter. J Neurosci 1998; 18: 4861-4869.

17. Panenka WJ, Procyshyn RM, Lecomte T, MacEwan GW, Flynn SW, Honer WG et al. Methamphetamine use: a comprehensive review of molecular, preclinical and clinical findings. Drug Alcohol Depend 2013; 129: 167-179.

18. Wu CW, Ping YH, Yen JC, Chang CY, Wang SF, Yeh CL et al. Enhanced oxidative stress and aberrant mitochondrial biogenesis in human neuroblastoma SH-SY5Y cells during methamphetamine induced apoptosis. Toxicol Appl Pharmacol 2007; 220: 243-251.

19. Abdul Muneer PM, Alikunju S, Szlachetka AM, Haorah J. Methamphetamine inhibits the glucose uptake by human neurons and astrocytes: stabilization by acetyl-L-carnitine. PLOS One 2011; 6: e19258.

20. Won S, Hong RA, Shohet RV, Seto TB, Parikh NI. Methamphetamine-associated cardiomyopathy. Clin Cardiol 2013; 36: 737-742.

21. Nakatani Y, Hara T. Disturbance of consciousness due to methamphetamine abuse. A study of 2 patients. Psychopathology 1998; 31: 131-137.

22. Silverstein PS, Shah A, Gupte R, Liu X, Piepho RW, Kumar S et al. Methamphetamine toxicity and its implications during HIV-1 infection. J Neurovirol 2011; 17: 401-415.

23. Shah A, Silverstein PS, Kumar S, Singh DP, Kumar A. Synergistic cooperation between methamphetamine and HIV-1 gsp120 through the P13K/Akt pathway induces IL-6 but not IL-8 expression in astrocytes. PLoS One 2012; 7: e52060.

24. Shah A, Kumar S, Simon SD, Singh DP, Kumar A. HIV gp120- and methamphetaminemediated oxidative stress induces astrocyte apoptosis via cytochrome P450 2E1. Cell Death Dis 2013; 4: e850.

25. Mizushima N. Autophagy: process and function. Genes Dev 2007; 21: 2861-2873.

26. Jackson WT, Giddings TH Jr., Taylor MP, Mulinyawe S, Rabinovitch M, Kopito RR et al. Subversion of cellular autophagosomal machinery by RNA viruses. PLOS Biol 2005; 3: e156.

27. Tsujimoto Y, Shimizu S. Another way to die: autophagic programmed cell death. Cell Death Differ 2005; 12(Suppl 2): 1528-1534.

28. Ma J, Wan J, Meng J, Banerjee S, Ramakrishnan S, Roy S. Methamphetamine induces autophagy as a pro-survival response against apoptotic endothelial cell death through the Kappa opioid receptor. Cell Death Dis 2014; 5: e1099.

29. Cao L, Walker MP, Vaidya NK, Fu M, Kumar S, Kumar A. Cocaine-mediated autophagy in astrocytes involves sigma 1 receptor, PI3K, mTOR, Atg5/7, Beclin-1 and induces type II programed cell death. Mol Neurobiol 2015; 53: 4417-3.

30. Castino R, Lazzeri G, Lenzi P, Bellio N, Follo C, Ferrucci M et al. Suppression of autophagy precipitates neuronal cell death following low doses of methamphetamine. J Neurochem 2008; 106: 1426-1439.

31. Zhao L, Zhu Y, Wang D, Chen M, Gao P, Xiao W et al. Morphine induces Beclin 1- and ATG5-dependent autophagy in human neuroblastoma SH-SY5Y cells and in the rat hippocampus. Autophagy 2010; 6: 386-394.

32. Boland B, Kumar A, Lee S, Platt FM, Wegiel J, Yu WH et al. Autophagy induction and autophagosome clearance in neurons: relationship to autophagic pathology in Alzheimer's disease. J Neurosci 2008; 28: 6926-6937.

33. Anglade P, Vyas S, Javoy-Agid F, Herrero MT, Michel PP, Marquez J et al. Apoptosis and autophagy in nigral neurons of patients with Parkinson's disease. Histol Histopathol 1997; 12: 25-31.

34. Sarkar S, Rubinsztein DC. Huntington's disease: degradation of mutant huntingtin by autophagy. FEBS J 2008; 275: 4263-4270.

35. Tien LT, Ho IK. Involvement of micro-opioid receptor in methamphetamine-induced behavioral sensitization. Curr Neuropharmacol 2011; 9: 215-218.
36. Whitfield TW Jr., Schlosburg JE, Wee S, Gould A, George O, Grant Y et al. Kappa opioid receptors in the nucleus accumbens shell mediate escalation of methamphetamine intake. J Neurosci 2015; 35: 4296-4305.

37. Georgiou P, Zanos P, Garcia-Carmona JA, Hourani S, Kitchen I, Laorden ML et al. Methamphetamine abstinence induces changes in mu-opioid receptor, oxytocin and CRF systems: association with an anxiogenic phenotype. Neuropharmacology 2016; 105: 520-532.

38. Colfax G, Shoptaw S. The methamphetamine epidemic: implications for HIV prevention and treatment. Curr HIV/AIDS Rep 2005; 2: 194-199.

39. Passaro RC, Pandhare J, Qian HZ, Dash C. The complex interaction between methamphetamine abuse and HIV-1 pathogenesis. J Neuroimmune Pharmacol 2015; 10: 477-486.

40. Hoefer MM, Sanchez AB, Maung R, de Rozieres CM, Catalan IC, Dowling CC et al. Combination of methamphetamine and HIV-1 gp120 causes distinct long-term alterations of behavior, gene expression, and injury in the central nervous system. Exp Neurol 2015; 263: 221-234.

41. Talloczy Z, Martinez J, Joset D, Ray Y, Gacser A, Toussi S et al. Methamphetamine inhibits antigen processing, presentation, and phagocytosis. PLOS Pathog 2008; 4: e28.

42. Melega WP, Cho AK, Harvey D, Lacan G. Methamphetamine blood concentrations in human abusers: application to pharmacokinetic modeling. Synapse 2007; 61: 216-220.

43. Riviere GJ, Gentry WB, Owens SM. Disposition of methamphetamine and its metabolite amphetamine in brain and other tissues in rats after intravenous administration. J Pharmacol Exp Ther 2000; 292: 1042-1047.

44. Oh SK, Cruikshank WW, Raina J, Blanchard GC, Adler WH, Walker J et al. Identification of HIV-1 envelope glycoprotein in the serum of AIDS and ARC patients. J Acquir Immune Defic Syndr 1992; 5: 251-256.

45. Nishikawa T, Mataga N, Takashima M, Toru M. Behavioral sensitization and relative hyperresponsiveness of striatal and limbic dopaminergic neurons after repeated methamphetamine treatment. Eur J Pharmacol 1983; 88: 195-203.

46. Yang MH, Kim S, Jung MS, Shim JH, Ryu NK, Yook YJ et al. Proteomic analysis of methamphetamine-induced reinforcement processes within the mesolimbic dopamine system. Addict Biol 2008; 13: 287-294.

47. Ford CP, Mark GP, Williams JT. Properties and opioid inhibition of mesolimbic dopamine neurons vary according to target location. J Neurosci 2006; 26: 2788-2797.

48. Faure A, Reynolds SM, Richard JM, Berridge KC. Mesolimbic dopamine in desire and dread: enabling motivation to be generated by localized glutamate disruptions in nucleus accumbens. J Neurosci 2008; 28: 7184-7192.

49. Cruz HG, Ivanova T, Lunn ML, Stoffel M, Slesinger PA, Luscher C. Bi-directional effects of GABA(B) receptor agonists on the mesolimbic dopamine system. Nat Neurosci 2004; 7: 153-159.

50. Ghitza UE, Preston KL, Epstein DH, Kuwabara H, Endres CJ, Bencherif B et al. Brain mu-opioid receptor binding predicts treatment outcome in cocaine-abusing outpatients. Biol Psychiatry 2010; 68: 697-703.

51. Lan KC, Ma T, Lin-Shiau SY, Liu SH, Ho IK. Methamphetamine-elicited alterations of dopamine- and serotonin-metabolite levels within mu-opioid receptor knockout mice: a microdialysis study. J Biomed Sci 2008; 15: 391-403.

52. Chiu CT, Ma T, Ho IK. Attenuation of methamphetamine-induced behavioral sensitization in mice by systemic administration of naltrexone. Brain Res Bull 2005; 67: 100-109.

53. Shippenberg TS, Chefer VI, Zapata A, Heidbreder CA. Modulation of the behavioral and neurochemical effects of psychostimulants by kappa-opioid receptor systems. Ann N Y Acad Sci 2001; 937: 50-73.

54. Battaglia G, Fornai F, Busceti CL, Aloisi G, Cerrito F, De Blasi A et al. Selective blockade of mGlu5 metabotropic glutamate receptors is protective against methamphetamine neurotoxicity. J Neurosci 2002; 22: 2135-2141.

55. Golembiowska K, Konieczny J, Wolfarth S, Ossowska K. Neuroprotective action of MPEP, a selective mGluR5 antagonist, in methamphetamine-induced dopaminergic neurotoxicity is associated with a decrease in dopamine outflow and inhibition of hyperthermia in rats. Neuropharmacology 2003; 45: 484-492.

56. Reichel CM, Schwendt M, McGinty JF, Olive MF, See RE. Loss of object recognition memory produced by extended access to methamphetamine self-administration is reversed by positive allosteric modulation of metabotropic glutamate receptor 5 . Neuropsychopharmacology 2011; 36: 782-792.

57. Osborne MP, Olive MF. A role for mGluR5 receptors in intravenous methamphetamine selfadministration. Ann N Y Acad Sci 2008; 1139: 206-211.

58. Mizushima N, Yoshimori T. How to interpret LC3 immunoblotting. Autophagy 2007; 3: 542-545.

59. Pattingre S, Tassa A, Qu X, Garuti R, Liang XH, Mizushima N et al. Bcl-2 antiapoptotic proteins inhibit Beclin 1-dependent autophagy. Cell 2005; 122: 927-939.

60. Marquez RT, Xu L. Bcl-2:Beclin 1 complex: multiple, mechanisms regulating autophagy/ apoptosis toggle switch. Am J Cancer Res 2012; 2: 214-221.

61. Gozuacik D, Kimchi A. Autophagy and cell death. Curr Top Dev Biol 2007; 78: 217-245.

62. Baehrecke EH. Autophagy: dual roles in life and death? Nat Rev Mol Cell Biol 2005; 6 : 505-510.

63. Duan $Y$, Ke J, Zhang H, He Y, Sun G, Sun X. Autophagic cell death of human hepatoma G2 cells mediated by procyanidins from Castanea mollissima BI. Shell-induced reactive oxygen species generation. Chem Biol Interact 2014; 224: 13-23. 
64. Gao Q, Liu H, Yao Y, Geng L, Zhang X, Jiang L et al. Carnosic acid induces autophagic cell death through inhibition of the Akt/mTOR pathway in human hepatoma cells. J Appl Toxicol 2015; 35: 485-492.

65. Gutierrez MG, Master SS, Singh SB, Taylor GA, Colombo MI, Deretic V. Autophagy is a defense mechanism inhibiting BCG and mycobacterium tuberculosis survival in infected macrophages. Cell 2004; 119: 753-766.

66. Nakagawa I, Amano A, Mizushima N, Yamamoto A, Yamaguchi H, Kamimoto $\mathrm{T}$ et al. Autophagy defends cells against invading group A Streptococcus. Science 2004; 306: 1037-1040.

67. Deretic V, Autophagy Levine B. immunity, and microbial adaptations. Cell Host Microbe 2009; 5: 527-549.

68. Killian MS. Dual role of autophagy in HIV-1 replication and pathogenesis. AIDS Res Ther 2012; 9: 16.

69. Eekels JJ, Sagnier S, Geerts D, Jeeninga RE, Biard-Piechaczyk M, Berkhout B. Inhibition of HIV-1 replication with stable RNAi-mediated knockdown of autophagy factors. Virol $J$ 2012; 9: 69.

70. Kyei GB, Dinkins C, Davis AS, Roberts E, Singh SB, Dong C et al. Autophagy pathway intersects with HIV-1 biosynthesis and regulates viral yields in macrophages. J Cell Biol 2009; 186: 255-268.

71. Spector SA, Zhou D. Autophagy: an overlooked mechanism of HIV-1 pathogenesis and neuroAIDS? Autophagy 2008; 4: 704-706.

72. Zhou D, Masliah E, Spector SA. Autophagy is increased in postmortem brains of persons with HIV-1-associated encephalitis. J Infect Dis 2011; 203: 1647-1657.

73. Banerjee A, Zhang X, Manda KR, Banks WA, Ercal N. HIV proteins (gp120 and Tat) and methamphetamine in oxidative stress-induced damage in the brain: potential role of the thiol antioxidant N-acetylcysteine amide. Free Radic Biol Med 2010; 48: 1388-1398.

74. Ronaldson PT, Bendayan R. HIV-1 viral envelope glycoprotein gp120 produces oxidative stress and regulates the functional expression of multidrug resistance protein-1 (Mrp1) in glial cells. J Neurochem 2008; 106: 1298-1313.
75. Steiner J, Haughey N, Li W, Venkatesan A, Anderson C, Reid R et al. Oxidative stress and therapeutic approaches in HIV dementia. Antioxid Redox Signal 2006; 8: 2089-2100.

76. Scherz-Shouval R, Elazar Z. ROS, mitochondria and the regulation of autophagy. Trends Cell Biol 2007; 17: 422-427.

77. Nazarko TY, Farre JC, Subramani S. Peroxisome size provides insights into the function of autophagy-related proteins. Mol Biol Cell 2009; 20: 3828-3839.

78. Yorimitsu T, Klionsky DJ. Eating the endoplasmic reticulum: quality control by autophagy. Trends Cell Biol 2007; 17: 279-285.

79. Lemasters JJ. Selective mitochondrial autophagy, or mitophagy, as a targeted defense against oxidative stress, mitochondrial dysfunction, and aging. Rejuvenation Res 2005; 8: 3-5.

80. Xiong Y, Contento AL, Nguyen PQ, Bassham DC. Degradation of oxidized proteins by autophagy during oxidative stress in Arabidopsis. Plant Physiol 2007; 143: 291-299.

(c) Cell Death and Disease is an open-access journal published by Nature Publishing Group. This work is licensed under a Creative Commons Attribution 4.0 International License. The images or other third party material in this article are included in the article's Creative Commons license, unless indicated otherwise in the credit line; if the material is not included under the Creative Commons license, users will need to obtain permission from the license holder to reproduce the material. To view a copy of this license, visit http://creativecommons.org/licenses/by/4.0/

(C) The Author(s) 2016

Supplementary Information accompanies this paper on Cell Death and Disease website (http://www.nature.com/cddis) 